\title{
PENERAPAN PROBLEM BASED LEARNING UNTUK MENINGKATKAN MINAT DAN KETERAMPILAN MENULIS TEKS EKSPLANASI
}

\author{
Gabriella Sophia Pinastiti, Andayani, Sumarwati \\ Universitas Sebelas Maret \\ Email: gabriellasophiap@student.uns.ac.id, andayani@staff.uns.ac.id, \\ sumarwati@staff.uns.ac.id
}

\begin{abstract}
Abstrak: Tujuan penelitian ini adalah untuk meningkatkan minat dan keterampilan menulis teks eksplanasi pada siswa kelas 8B SMP Kristen Satya Wacana Salatiga dengan menerapkan model problem based learning. Penelitian ini merupakan penelitian tindakan kelas yang dilaksanakan dalam dua siklus. Kegiatan yang dilakukan dalam tahap pelaksanaan terdiri dari lima tahapan sesuai dengan model problem based learning, yaitu 1) orientasi masalah, 2) mengorganisasikan siswa untuk penyelidikan, 3) membimbing penyelidikan, 4) mengembangkan dan menyajikan hasil, serta 5) menganalisis dan mengevaluasi pemecahan masalah. Berdasarkan hasil penelitian dapat disimpulkan bahwa penerapan model problem based learning dapat meningkatkan minat dan keterampilan menulis teks eksplanasi pada siswa kelas 8B SMP Kristen Satya Wacana Salatiga. Menurut hasil analisis, minat menulis teks eksplanasi siswa pada siklus I sebesar $50 \%$ atau sebanyak 10 siswa, meningkat pada siklus II sebesar 85\% atau sebanyak 17 siswa. Sedangkan keterampilan menulis teks eksplanasi menunjukkan hasil yang signifikan. Pada siklus I sebesar 65\% atau sebanyak 13 siswa, meningkat pada siklus II 100\% atau seluruh siswa telah berhasil mencapai nilai Kriteria Ketuntasan Minimal yang telah ditentukan sebelumnya yaitu 75 .
\end{abstract}

Kata kunci : minat, keterampilan menulis, teks eksplanasi, problem based learning

\section{IMPLEMENTATION OF PROBLEM BASED LEARNING TO INCREASE STUDENT' INTEREST AND WRITING SKILL OF EXPLANATORY TEXT}

\begin{abstract}
The aim of this study was to improve: the students' interest and text writing skills towards the explanatory text for 8th-grade students of SMP Kristen Satya Wacana Salatiga by applying a problem-based learning model. This study is a classroom action research conducted in two cycles. Acctivities carried out in the implementation phase consist of five stages in accordance with the problem based learning, namely (1) problem orientation, (2) organizing students for investigation, (3) guiding investigation, (4) developing and presenting results, and (5) analyzing and evaluating promblem solving. According to the results of the analysis, the students' interest toward explanatory texts is the first cycle was $50 \%$ or as many as 10 students, in the second cycle the students' interest increased becoming $85 \%$ or as many as 17 students. While the results of explanatory text writing skills showed significant results. In the first cycle, the students' interest in explanation text is $65 \%$ or as many as 13 students. Then, it increased in the second cycle which is $100 \%$ or all students have succeeded in achieving the minimum completeness criteria that have been determined previously, which is 75 .
\end{abstract}

Keywords: the students' interest, text writing skills, the explanatory text, problem based learning

\section{PENDAHULUAN}

Peran guru dalam pembelajaran adalah sebagai pengelola atau manager, organisator dan fasilitator selama pembelajaran. Dalam menjalani perannya, guru memiliki kewajiban untuk menghasilkan pembelajaran yang efektif dan bermakna. Pembelajaran efektif bisa dirumuskan sebagai "Pembelajaran yang berhasil mewujudkan pembelajaran sebagaimana dikehendaki oleh guru. Ada dua elemen sederhana dalam pembelajaran efektif yaitu guru harus secara pasti memiliki ide yang jelas terkait pembelajaran apa yang hendak disampaikan, dan pengalaman belajar yang dibangun untuk mewujudkan hal tersebut" (Kyriacou, 2009: 15). 
Pendapat lain mengatakan bahwa pembelajaran efektif harus terencana. Menurut Hattie (2012: 42), rencana pembelajaran harus disusun dengan mendalam mengenai pengetahuan dan keterampilan awal yang telah dimiliki oleh siswa, apa yang sudah mereka ketahui dan apa yang sudah mereka lakukan. Hal ini berguna bagi penentuan target atau hasil yang harus diraih oleh setiap siswa di akhir pembelajaran. Guru harus mampu menciptakan pembelajaran yang bermakna.

Kurikulum 2013 (Kemendikbud 2013). merupakan kurikulum yang menempatkan mata pelajaran bahasa Indonesia dalam kedudukan yang penting. Bahasa Indonesia sebagai penghela ilmu pengetahuan menjadikan bahasa Indonesia sebagai bahasa pengantar ilmu pengetahuan antar mata pelajaran. Siswa diharapkan mampu menguasai empat keterampilan berbahasa yaitu menyimak, berbicara, membaca dan menulis. Salah satunya adalah teks eksplanasi.

Teks eksplanasi merupakan salah satu teks yang diajarkan dalam mata pelajaran bahasa Indonesia sesuai Kurikulum 2013 untuk jenjang SMP/MTs. Teks eksplanasi merupakan materi baru yang diajarkan di sekolah sehingga sebagian besar siswa belum sepenuhnya menguasai materi yang berkaitan dengan teks eksplanasi.

Berdasarkan hasil observasi yang dilakukan oleh peneliti terhadap proses pembelajaran menulis teks eksplanasi di kelas tempat penelitian ditemukan bahwa keterampilan menulis teks eksplanasi yang dimiliki oleh siswa masih rendah. Diketahui pula bahwa model pembelajaran yang digunakan oleh guru belum tepat dan guru merasa kesulitan dalam mencari model pembelajaran yang menarik bagi siswa. Hal itu diksebabkan oleh kurang memadainya model atau pendekatan penelitian yang dipakai (Suhardi dan Santoso, 2011: 160).

Proses pembelajaran pada Kurikulum 2013 untuk jenjang SMP dilaksanakan menggunakan pendekatan saintifik. Proses pembelajaran tersebut menyentuh tiga ranah, yaitu sikap, pengetahuan, dan keterampilan. Dalam proses pembelajaran berbasis pendekatan ilmiah, ranah sikap mengandung materi ajar agar siswa "tahu mengapa". Ranah keterampilan mengandung materi ajar agar siswa "tahu bagaimana". Ranah pengetahuan mengandung materi ajar agar siswa "tahu apa". Hasil akhirnya adalah peningkatan dan keseimbangan antara kemampuan untuk menjadi manusia yang baik (soft skill) dan manusia yang memiliki kecakapan dan pengetahuan untuk hidup secara layak (hard skill) dari siswa yang meliputi aspek kompetensi sikap, keterampilan, dan pengetahuan (Kemendikbud 2013).

Dengan menerapkan problem based learning siswa tidak hanya diasah pengetahuannya saja namun juga keterampilannya dalam memecahkan masalah sehari-hari. Problem based learning memungkinkan untuk melatih siswa dalam mengintegrasikan pengetahuan dan keterampilan secara simultan serta mengaplikasikannya dalam konteks yang relevan. Selain itu, tujuan belajar menggunakan model problem based learning terkait dengan penguasaan materi pengetahuan, keterampilan menyelesaikan masalah, belajar multidisiplin, dan keterampilan hidup" (Tan dalam Sani 2014:129).

Model problem based learning mampu menuntun siswa untuk aktif melakukan penyelidikan dalam menyelesaikan masalah. Adapun masalah tersebut dapat berfungsi sebagai materi dan topik tulisan siswa. Menurut hasil penelitian Sumarwati (2019) bahwa pada prapenulidan, siswa perlu diberi bantuan dalam mengadakan topik, antara lain gambar, hasil pengamatan, serta masalah yang dipecahkan.

Dalam model pembelajaran ini, siswa aktif mencari dan menemukan pengetahuannya sendiri, sedangkan guru berperan sebagai fasilitator atau pembimbing (Tan dalam Sani 2014:129).. 
Pembelajaran akan membentuk kemampuan berpikir tingkat tinggi (higher order thinking skills) dan meningkatkan kemampuan siswa untuk bepikir kritis.

\section{METODE PENELITIAN}

\section{Tempat dan Waktu Penelitian}

Penelitian ini dilaksanakan di kelas 8B SMP Kristen Satya Wacana Salatiga. Siswa kelas 8B berjumlah 20, laki-laki 11 siswa dan perempuan 9 siswa. Rencana tahap pengajuan hingga tahap pelaporan membutuhkan waktu kurang lebih tujuh bulan. Terhitung sejak awal bulan Desember 2018.

\section{Desain Penelitian}

Desain penelitian ini menggunakan prosedur penelitian tindakan kelas (PTK) yang digunakan untuk meningkatkan kualitas pembelajaran baik proses maupun hasil. "Penelitian tindakan kelas adalah tindakan nyata yang dilakukan guru (dan bersama pihak lainnya) untuk memecahkan masalah yang dialami dalam proses belajar mengajar" (Suwandi, 2008: 16) .

PTK merupakan penelitian kolaboratif yang melibatkan peneliti, guru, siswa maupun karyawan sekolah yang bertujuan untuk meningkatkan kualitas pembelajaran baik proses maupun hasil. Penelitian tindakan kelas dilaksanakan melalui proses pengkajian berdaur yang terdiri atas empat tahap, yaitu (1) perencanaan, (2) tindakan, (3) observasi, dan (4) refleksi. Penelitian tindakan kelas ini dibagi menjadi dua siklus, yaitu siklus I dan siklus II (Arikunto, dkk 2006: 62).

\section{Tenik Pengumpulan dan Analisis Data}

Bentuk instrumen tes yaitu tes menulis teks eksplanasi. Tes menulis teks eksplanasi adalah tes untuk mendeskripsikan urutan terjadinya suatu peristiwa alam maupun sosial. Tes ini bertujuan untuk mengetahui keterampilan siswa dalam menulis teks eksplanasi melalui model problem based learning.
Observasi kepada guru dilakukan untuk mengetahui keterampilan guru dalam merangsang minat siswa untuk menulis teks eksplanasi. Sementara itu, observasi terhadap siswa dilakukan untuk mengetahui perilaku dan keterampilan siswa selama mengikuti pembelajaran menulis teks eksplanasi.

Wawancara mendalam dilakukan secara tidak formal terstruktur guna mendapatkan data yang tidak bisa didapat melalui teknik observasi. Untuk itu, peneliti melakukan wawancara secara langsung. Peneliti melakukan wawancara kepada siswa dan guru bahasa Indonesia kelas 8B SMP Kristen Satya Wacana Salatiga sebagai subjek penelitian.

Analisis dokumen dilakukan untuk mengetahui peningkatan keterampilan menulis teks eksplanasi siswa selama dilaksanakan tindakan. Dokumen berupa hasil tulisan siswa dinilai untuk mengetahui keberhasilan pelaksanaan tindakan. Teknik kedua yang digunakan dalam penelitian ini adalah teknik deskriptif komparatif. yaitu membandingkan hasil dari tiap siklus dalam penelitian ini. hasil dari setiap siklus dibandingkan untuk kemudian diamati peningkatan minat dan keterampilan menulis teks eksplanasi siswa setelah dilaksanakannya model problem based learning. Sejalan dengan pendapat tersebut, dekriptif komparatif yaitu teknik analisis yang membandingkan nilai tes antarsiklus dengan indikator kerja (Yoni, dkk, 2010: 3-5). Peningkatan tersebut dicatat untuk membuktikan keberhasilan penelitian ini.

\section{Prosedur Tindakan Siklus}

Dalam penelitian tindakan kelas siklus I terdapat empat tahapan yang harus dilakukan. Tahapan-tahapan rencana tindakan dalam penelitian siklus adalah tahap perencanaan, pelaksanaan rencana pembelajaran (tidakan), observasi, dan refleksi. 


\section{HASIL DAN PEMBAHASAN \\ Deskripsi Pratindakan}

Kegiatan yang dilakukan pada tahap ini berupa observasi pembelajaran di dalam kelas, pemberian angket, dan wawancara dengan siswa dan guru. Dari hasil observasi diketahui kondisi nyata siswa dan keadaan kelas pada saat kegiatan proses pembelajaran berlangsung. Serta diperoleh simpulan mengenai kondisi yang terjadi pada saat pembelajaran menulis teks eksplanasi bahwa sebanyak 5 siswa (25\%) aktif selama mengikuti pembelajaran teks eksplanasi, sedangkan 15 siswa (75\%) lainnya kurang aktif.

Berdasarkan analisis terhadap hasil menulis teks eksplanasi yang telah dilakukan oleh siswa, diketahui bahwa siswa yang sudah lulus di atas batas Kriteria Ketuntasan Minimal (KKM) sebanyak 2 siswa (10\%), sedangkan sebanyak 18 siswa (90\%) memperoleh nilai kurang dari batas KKM. KKM yang digunakan untuk matapelajaran Bahasa Indonesia di kelas 8 SMP Kristen Satya Wacana Salatiga adalah 75.

Dari hasil pratindakan, diketahui skor tertinggi pembelajaran menulis teks eksplanasi sebelum menggunakan model pembelajaran berbasis masalah adalah 79 , sedangkan skor terendah adalah 45 . Apabila dilihat dari kriteria teks eksplanasi. Terdapat 7 siswa yang tulisannya sudah memenuhi kriteria teks eksplanasi. Sedangkan 13 siswa lainnya belum menunjukkan kriteria teks eksplanasi.

Hasil menulis teks eksplanasi sebelum dilakukannya model pembelajaran berbasis masalah dapat disajikan dalam Tabel 1.

Berdasarkan observasi awal, peneliti berdiskusi dengan guru untuk menentukkan langkah selanjutnya. Diskusi yang dilakukan bertujuan untuk meningkatkan minat siswa dalam pembelajaran menulis teks eksplanasi dan untuk memperbaiki keterampilan menulis teks eksplanasi sehingga kualitas pembelajaran meningkat. Hasil diskusi antara peneliti dan guru menyepakati untuk menerapkan model problem based learning dalam pembelajaran menulis teks eksplanasi.

Tabel 1. Distribusi Frekuensi Nilai Kemampuan Menulis Teks Eksplanasi pada Prasiklus

\begin{tabular}{ccc}
\hline Interval & $\mathrm{f}$ absolut & f relatif $(\%)$ \\
\hline $45-50$ & 1 & $5 \%$ \\
\hline $51-55$ & 5 & $25 \%$ \\
\hline $56-60$ & 4 & $20 \%$ \\
\hline $61-65$ & 2 & $10 \%$ \\
\hline $66-70$ & 1 & $5 \%$ \\
\hline $71-75$ & 5 & $25 \%$ \\
\hline $76-80$ & 2 & $10 \%$ \\
\hline Jumlah & 20 & $100 \%$ \\
\hline
\end{tabular}

\section{Deskripsi Tindakan Siklus 1}

Siklus I pertemuan pertama dilaksanakan pada hari Rabu, 31 Januari 2019. Pertemuan kedua dilaksanakan pada hari Jumat, 1 Februari 2019. Seluruh peserta didik bersiap menerima materi yang akan disampaikan oleh guru. Pada inti pembelajaran kelas dibagi menjadi 5 kelompok. Guru memberi masalah yang berebda pada kelima kelompok tersebut untuk ditemukan penyebabnya dan solusinya. Selanjutnya siswa secara invidual menulis hasil pemecahan masalah dalam bentuk teks eksplanasi yang meliputi 3 bagian struktur, yaitu pernyataan umum, rincian proses, ddan penafsiran.

Dari dua kali pertemuan siklus I, terdapat beberapa perubahan dalam pembelajaran baik dari minat siswa selama pembelajaran maupun keterampilan menulis teks eksplanasi siswa. Berdasarkan hasil siklus I, dapat diketahui bahwa nilai tertinggi keterampilan menulis teks eksplanasi siswa kelas 8B SMP Kristen Satya Wacana Salatiga adalah 87, sedangkan nilai terendah 58.Yang mendapat nilai 75 ke atas sebanyak 65\% sehingga dapat dinyatakan siswa yang dapat mencapai KKM adalah 65\%, 
sedangkan yang belum mencapai KKM $35 \%$.

Perolehan nilai menulis teks eksplanasi siswa SMP Kristen Satya Wacana Salatiga dapat disajikan pada tabel 2.

Tabel 2. Distribusi Frekuensi Nilai Keterampilan Menulis Teks Eksplanasi pada Siklus I

\begin{tabular}{ccc}
\hline Interval & f absolut & f relatif $(\%)$ \\
\hline \hline $55-59$ & 1 & $5 \%$ \\
\hline $60-64$ & 1 & $5 \%$ \\
\hline $65-69$ & 3 & $15 \%$ \\
\hline $70-74$ & 2 & $10 \%$ \\
\hline $75-79$ & 6 & $30 \%$ \\
\hline $80-84$ & 5 & $25 \%$ \\
\hline $85-89$ & 2 & $10 \%$ \\
\hline \hline Jumlah & 20 & $100 \%$ \\
\hline \hline
\end{tabular}

\section{Deskripsi Siklus II}

Siklus dua dilaksanakan dalam dua kali pertemuan, yaitu pada hari Rabu, 6 Februari 2019 dan Kamis 7 Februari 2019. Guru bersama peneliti memasuki kelas bersamaan. Seperti biasa, ketua kelas memimpin teman-temannya untuk memberi salam. Guru menjawab salam tersebut dan mempersilahkan para siswa untuk duduk kembali. Pada inti pembelajaran kelas dibagi menjadi 5 kelompok. Guru memberi masalah yang berebda pada kelima kelompok tersebut untuk ditemukan penyebabnya dan solusinya. Selanjutnya siswa secara invidual menulis hasil pemecahan masalah dalam bentuk teks eksplanasi yang meliputi 3 bagian struktur, yaitu pernyataan umum, rincian proses, ddan penafsiran.

Berdasarkan lembar observasi minat menulis teks eksplanasi siswa, diperoleh data bahwa 17 siswa (85\%) aktif selama pembelajaran berlangsung, 2 siswa (10\%) belum aktif, dan 1 siswa (5\%) yang tidak aktif dalam pembelajaran. Berdasarkan hasil menulis teks eksplanasi siswa diketahui bahwa 20 siswa sudah mencapai batas nilai Kriteria Ketuntasan Minimal
(KKM). Hal ini menunjukkan bahwa keseluruhan siswa (100\%) sudah lulus dalam menulis teks eksplanasi. Diketahui bahwa nilai tertinggi keterampilan menulis teks eksplanasi siswa adalah 95, sedangkan nilai terendah adalah 83 .

Hasil menulis teks eksplanasi dengan model problem based learning siswa kelas 8B SMP Kristen Satya Wacana Salatiga pada siklus II, dapat disajikan dalam Tabel 3.

Tabel 3. Distribusi Frekuensi Nilai Kemampuan

\begin{tabular}{ccc}
\multicolumn{3}{c}{ Menulis Teks Eksplanasi pada Siklus II } \\
\hline Interval & $\mathrm{f}$ absolute & frelatif $(\%)$ \\
\hline \hline $75-79$ & 4 & $20 \%$ \\
\hline $80-84$ & 3 & $15 \%$ \\
\hline $85-89$ & 7 & $35 \%$ \\
\hline $90-95$ & 6 & $30 \%$ \\
\hline \hline Jumlah & 20 & $100 \%$ \\
\hline \hline
\end{tabular}

Secara garis besar, penelitian yang telah dilakukan pada dua siklus dengan menerapkan model problem based learning dalam pembelajaran menulis teks eksplanasi telah berjalan lancar dan sesuai dengan rencana. Minat dan keaktifan siswa selama pembelajaran menulis teks eksplanasi terlihat mengalami peningkatan. Siswa memberikan respon yang baik dalam pembelajaran selama dua siklus ini. Kekurangan yang terjadi di siklus I sudah teratasi dengan baik pada siklus II. Secara kualitas, keterampilan menulis teks eksplanasi siswa sudah menunjukan peningkatan. Seluruh siswa telah mencapai batas nilai KKM yang telah ditetapkan sehingga seluruh siswa telah lulus mengikuti pembelajaran menulis teks eksplanasi ini. Hal ini menunjukkan bahwa model problem based learning mampu membantu siswa dalam pembelajaran menulis teks eksplanasi. Pada siklus II, proses dan hasil pembelajaran menulis teks eksplanasi telah meningkat dibandingkan dengan siklus I. Minat dan keterampilan siswa menulis teks eksplanasi telah meningkat. Didasarkan pada indikator 
penilaian yang dihasilkan, telah menunjukkan hasil yang memuaskan.

\section{Pembahasan}

Keaktifan siswa di tiap siklus menunjukkan peningkatan. Pada siklus I siswa yang aktif selama pembelajaran sebanyak 10 siswa $(50 \%)$ meningkat sebanyak 17 siswa (85\%) pada siklus II. Selama pembelajaran siswa menjadi aktif dan tertarik. Hal ini dibuktikan dengan respon siswa terhadap pembelajaran seperti bertanya, menjawab, dan menanggapi guru. Peningkatan ini terjadi karena guru telah menggunakan metode yang merangsang siswa agar aktif selama pembelajaran, pembelajaran tidak lagi berpusat kepada guru melainkan kepada siswa.

Kualitas pembelajaran menulis teks eksplanasi mengalami peningkatan. Hal ini terlihat dari indikator proses pembelajaran yang mengalami peningkatan di setiap siklus. Tindakan berupa penerapan model problem based learning yang dilaksanakan di tiap siklus mampu meningkatkan kualitas proses pembelajaran siswa kelas 8B SMP Kristen Satya Wacana Salatiga.

Dari hasil penelitian, diketahui bahwa proses pembelajaran menulis teks eksplanasi pada siklus I mencapai $65 \%$, meningkat lebih baik dari prasiklus yang hanya mencapai ketuntasan sebanyak $10 \%$. Maka dapat dikatakan bahwa tindakan yang dilakukan guru untuk meningkatkan kualitas proses pembelajaran telah berhasil. Hal ini membuktikan model pembelajaran berbasis masalah memiliki peran dalam meningkatkan kualitas belajar mengajar.

Berikut grafik peningkatan persentase peningkatan kualitas proses pembelajaran menulis teks eksplanasi dengan model problem based learning siswa kelas 8B SMP Kristen Satya Wacana Salatiga.

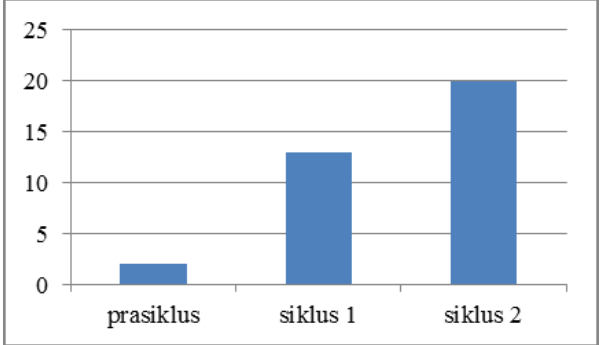

Gambar 1. Grafik Ketuntasan Keterampilan Menulis Teks Eksplanasi Siswa Kelas VIII B SMP Kristen Satya Wacana Salatiga Menggunakan Model Pembelajaran Berbasis Masalah

Media gambar yang dipilih guru untuk digunakan dalam meningkatkan keterampilan menulis teks eksplanasi siswa telah berhasil dilaksanakan. Berdasarkan hasil wawancara yang dilakukan, siswa merasa sangat terbantu dengan media gambar yang diberikan guru. Ide dan gagasan yang dimiliki siswa dapat optimal dituangkan dalam menulis teks eksplanasi. Hal ini sejalan dengan meningkatnya hasil yang diperoleh siswa.

Temuan ini relevan dengan penelitian Hizati, dkk (2018) dalam artikelnya yang berjudul Pengaruh Model Problem Based Learning Berbantuan Media Gambar Berseri Terhadap Keterampilan Menulis Teks Eksplanasi Siswa Kelas VIII SMP Negeri 12 Padang yang telah berhasil dilaksanakan. Penemuan ini sejalan dengan penelitian yang telah dilakukan Andayani, dkk (2017) dalam artikelnya yang berjudul Peningkatan Kemampuan Menulis Teks Eksplanasi dengan Menggunakan Media Audiovisual pada Siswa Sekolah Menengah Pertama.

\section{SIMPULAN}

Penerapan model problem based learning dapat meningkatkan minat siswa dalam mengikuti pembelajaran menulis teks eksplanasi. Peningkatan tersebut terlihat dari berhasilnya proses dan hasil belajar siswa dalam menulis teks eksplanasi menggunakan model problem based learning. Persentase minat siswa meningkat dari $50 \%$ di siklus I menjadi $85 \%$ di siklus II. 
Penerapan model problem based learning dapat meningkatkan keterampilan menulis teks eksplanasi siswa kelas 8B SMP Kristen Satya Wacana Salatiga. Hal ini ditandai dengan besarnya persentase ketuntasan siswa dalam mencapai nilai KKM yang telah ditetapkan yaitu 75. Pada prasiklus, persentase ketuntasan siswa sebanyak 2 siswa (10\%), pada siklus I

\section{REFERENSI}

Alwi, H. Dardjowodjojo, S. Lapoliwa, H. \&Moeliono, A.M. (2010). Tata Bahasa Baku Bahasa Indonesia. Jakarta: Balai Pustaka.

Arikunto, S. (2010). Penelitian Tindakan. Yogyakarta: Aditya Media.

Amri, S \& Ahmadi, I.K. (2010). Proses Pembelajaran Kreatif danInovatif dalam Kelas. Jakarta: PT. Prestasi Pustakaraya.

Anam, K. (2012). "Peningkatan Ketrampilan Menulis Paragraf Persuasi Melalui Model Pembelajaran Berbasis Masalah Dengan Media Kliping Berita Media Cetak Siswa Kelas X A SMA Negeri 1 Gemuh Kabupaten Kendal". Skripsi. Unnes.

Andayani., Darmuki, A., Nurkamto, J., \& Saddhono, K. (2018,). Cooperative, Synectics, and CTL Learning Models toward Speaking Ability Viewed from Student's Motivation. In 1st International Conference on Intellectuals' Global Responsibility (ICIGR 2017). AtlantisPress.

Andayani., Rukayah, R., \& Slamet, Y. (2018). The Implementation of Cooperative Learning Approach with Multimedia for Children's Literature Learning at Elementary School in the Characters Building Perspective. International Journal of Pedagogy and Teacher Education, 2(1), 97-106.

Andyani, N., Saddhono, K., \&Mujyanto, Y. (2017). Peningkatan Kemampuan Menulis Teks Eksplanasi dengan meningkat sebanyak 13 siswa (65\%), dan pada siklus II mencapai 20 siswa atau (100\%). Dengan demikian, dapat disimpulkan bahwa penerapan model problem based learning mampu meningkatkan minat dan keterampilan siswa dalam pembelajaran menulis teks eksplanasi.

Menggunakan Media Audiovisual pada Siswa Sekolah Menengah Pertama. BASASTRA, 4(2), 161-174.

Anderson, M. \& Anderson, K. (1997). Text Type in English 1. Australia: Macmillan Education Australia PTY LTD.

Andrianto. (2014). "Peningkatan Keterampilan Menulis Teks Eksplanasi dengan Menggunakan Model "CIRC" yang Berbantuan Media Video Animasi Bencana Alam pada Siswa Kelas VII C SMP N 1 Bobotsari Kabupaten Purbalingga". Skripsi. Unnes.

Arief, E., Hizati, A., \& Syahrul, R. (2018). Pengaruh model problem basedlearningberbantuan media gambar berseri terhadap keterampilan menulis teks eksplanasi siswa kelas viii smp negeri 12 padang. Pendidikan Bahasa dan Sastra Indonesia, 7(1), 183-190.

CokerJr, D. L., Jennings, A. S., FarleyRipple, E., \& MacArthur, C. A. (2018). When the type of practicematters: The relationship between typical writing instruction, student practice, and writing achievement in first grade. Contemporary Educational Psychology, 54, 235-246.

Emilia, E. (2011). Pendekatan GenreBased dalam Pengajaran Bahasa Inggris:Petunjuk untuk Guru. Bandung: Rizqi Press. 
Gultom, P. (2014). Pengaruh Penerapan Model Pembelajaran Berbasis Masalah Terhadap Kemampuan Menulis Teks Eksplanasi Siswa Kelas VII SMP Santo Ignasius Medan Tahun Pembelajaran 2013/2014 (Doctoral dissertation, UNIMED).

Handayani, S. (2009). "Efektifitas Penerapan Model Pembelajaran Berbasis Masalah (Problem Based Learning) dan Pembelajaran Kooperatif (Cooperative Learning) Tipe Jigsaw untuk Meningkatkan Aktivitas Belajar, Hasil Belajar dan Respon Belajar Siswa pada Mata Pelajaran Ekonomi di SMA Negeri 2 Malang" dalam JPE-Volume 2, Nomor 1.

Hattie, J. (2012). Visible Learning For Teachers: Maximizing Impact On Learning. London and New York: Routledge.

Hizati, A., Syahrul, R., \& Arief, E. (2018). Pengaruh Model Problem Based Learning Berbantuan Media Gambar Berseri Terhadap Keterampilan Menulis Teks Eksplanasi Siswa Kelas Viii SMP Negeri 12 Padang. Pendidikan Bahasa dan Sastra Indonesia, 7(1), 183-190.

Iskandarwassid \& Sunendar, D. (2011). Strategi Pembelajaran Bahasa. Bandung: PT. RosdakaryaOffset.

Jalaluddin, I., Yunus, M. M., \&Yamat, H. (2011). Improving Malaysian rural learners' writing skill: A case study. Procedia-Social and Behavioral Sciences, 15, 1845-1851.

Joyce, Bruce, Marsha Weil, Emily Calhoun. (2009). Models of Teaching: Model-Model Pengajaran Edisi 8 (Terjemahan Aachmad Fawaid dan Ateilla Mirza). Yogyakarta: Pustaka Pelajar.

Kemendikbud. (2013). Bahan Diklat untuk Guru: Dalam rangka Implementasi Kurikulum 2013. Jakarta: Kemendikbud.
Kosasih, E. \& Restuti. (2013). Mandiri: Bahasa Indonesia untuk SMP/MTsKelasVII. Jakarta: Erlangga.

Kyriacou, C. (2009). Effective Teachng: Theory and Practice. Bandung: Nusa Media.

Mahsun. 2013. "Pembelajaran Bahasa Indonesia Menggunakan Pendekatan Teks". Kompas Edu. 27 Februari 2013.

Munandar. (2003). Psikologi Guruan. Jakarta: PT. Rajagrafindo Persada.

Nurgiyantoro, B. (2010). Penelitian Pembelajaran Bahasa Berbasis Kompetensi. Yogyakarta: IKAPI.

Purwaningrum, S. W. (2013). Penggunaan Metode Peta Pikiran (Mind Mapping) Untuk Meningkatkan kemampuan Menulis Narasi Siswa Sekolah Menengah Pertama. BASASTRA Jurnal Penelitian Bahasa, Sastra Indonesia dan Pengajarannya, 2(1), 1-13.

Saefullah. (2012). Psikologi Perkembangan dan Guruan. Bandung: CV. Pustaka Setia.

Sani, R.A. (2014). Pembelajaran Saintifik untuk ImplementasiKurikulum 2013. Jakarta: Bumi Aksara.

Sardirman. (1994). Interaksi Belajar dan Mengajar. Jakarta: PT. Rajagrafindo Persada.

Schunk, D, H., dkk. (2012). Motivasi dalam Guruan. Jakarta: PT. Indeks.

Slameto. (1995). Belajar dan Faktor-faktor yang Mempengaruhinya. Jakarta: PT. Rineka Cipta.

Sudjana, N. (2005). Penelitian Hasil Proses Belajar Mengajar. Bandung: PT. Remaja RosdakaryaOffset.

Suhardi \& Santoso, J. (2011). Analisis Kontrastif Bahasa Indonesia, Jawa, dan Banjar sebagai Sasar Penyusunan Model Pembelajaran Bahasa Indonesia Permulaan. Litera. 2(10). 159-170.

Sumarwati. (2019). Peningkatan Kualitas Pembelajaran Menulis melalui Pendekatan Proses pada Siswa di 
Kelas V Sekolah Dasar, Jurnal Logat, 6(2), 151-167.

Suprijono, A. (2010). Cooperative Learning: Teori \& Aplikasi PAIKEM. Yogyakarta: Pustaka Pelajar.

Sutopo, H.B. (2006). Metodologi Penelitian Kuantitatif.: Dasar, Teori, dan Terapannya dalam Penelitian. Surakarta: UNS Press.

Suwandi, J. (2011). Penelitian Tindakan Kelas. Surakarta: PSKGJ-FKIP Universitas Muhammadiyah Surakarta.

Tarigan, H.G. (2008). Menulis sebagai Suatu Keterampilan Berbahasa. Bandung: Angkasa.

Yew, E. H., \&Goh, K. (2016). Problembased learning: an overview of its process and impact on learning. Health Professions Education, 2(2), 75-79.

Yoni, A. (2010). Menyusun Penelitian Tindakan Kelas. Yogyakarta: Familia Pustaka Keluarga. 